\title{
Microstructures, Mechanical Properties, and Erosion Resistance of Unbalanced Magnetron Sputtering Deposited TiN/VN Nano-structured Coatings
}

\author{
Qi Yang • Mariusz Bielawski • Robert C. McKellar
}

Received: 29 May 2012/in revised form: 14 August 2012/Published online: 15 September 2012

(C) Springer Science+Business Media, LLC and ASM International 2012

\begin{abstract}
Nano-structured TiN/VN coatings with a range of bi-layer periods from 3.4 to $11.0 \mathrm{~nm}$ were deposited on ferromagnetic 410 stainless steel (410SS) and non-ferromagnetic Ti-6Al-4V titanium alloy substrates using an Unbalanced Magnetron Sputtering (UMS) technique; the microstructure, mechanical properties, and erosion performance of the as-sputtered coating were evaluated. While the surface morphologies of the coatings on these two substrates were different, the XRD measurements complemented by a texture evaluation through pole figures indicated that the preferred orientations of the TiN/VN coatings on 410SS and Ti-6Al-4V were also dissimilar. A nano-mechanical indentation technique was used to determine hardness and Young's modulus, and it was found that these parameters varied with superlattice bi-layer period and were dependent on the type of substrate material. Furthermore, the erosion resistances of the TiN/VN coatings were markedly higher than the bare substrate counterparts, and were influenced by the substrate type. Specifically, the differences in the microstructures and properties of the coatings were attributed to the difference in ion flux during the UMS deposition due to the dissimilar magnetic properties of the substrate materials.
\end{abstract}

Keywords Aerospace - Coatings - Surface engineering · Tribology

Q. Yang $(\bowtie) \cdot$ M. Bielawski · R. C. McKellar

Aerospace Portfolio, National Research Council of Canada,

1200 Montreal Road, Ottawa, ON K1A 0R6, Canada

e-mail: Qi.Yang@nrc-cnrc.gc.ca

\section{Introduction}

Erosion-resistant coatings are used to protect compressor components of land and airborne gas turbines from destructive effects of dust and sand particles suspended in the inflowing air [1-3]. To achieve improved erosion resistance on these components, novel materials and new design approaches in protective coatings are being explored [3-5]. Transition metal nitrides have been successfully used for years as protective coatings with high degree of wear and erosion resistance. Most commonly, these materials are deposited by physical vapor deposition (PVD), a process that allows for further enhancement of individual coating properties through multi-layered and nano-structured design [6, 7]. This approach is of particular importance in the case of erosion-resistant coatings, where high hardness and fracture toughness are required [7, 8].

As the traditional methods of developing erosion-resistant coatings through trial-and-error experimentation are time-consuming and costly, computer modeling using the finite element (FE) approach or density functional theory (DFT) calculation are often utilized. These techniques can speed up the design process by identifying new materials and improved coating architectures, and by providing materials data, such as fracture toughness, that are not easily available for thin film materials [9]. The TiN/VN superlattice system, one of the materials evaluated in the latter DFT study, demonstrates a good potential for having high fracture toughness. A TiN/VN superlattice coating, because of its nano-layered structure, was also shown to exhibit an excellent capability in hardness enhancement [10].

In this study, nano-structured TiN/VN coatings were deposited on 410 stainless steel and Ti-6Al-4V substrates. The microstructure, mechanical properties, and solid particle erosion performance of the coatings were examined 
with a view toward exploring their potential application as erosion-resistant coatings for compressor components of gas turbine engines.

\section{Experimental}

Two compressor blade materials, titanium alloy Ti-6Al-4V and 410 stainless steel were chosen as substrate materials. The nano-structured TiN/VN coatings were deposited on mirror-polished flat coupons by reactive sputtering using a closed-field unbalanced magnetron sputtering (UMS) coater. A mixed gas of $\mathrm{Ar}$ and $\mathrm{N}_{2}$ was used with the $\mathrm{Ar}$ flow rate set at $15 \mathrm{sccm}$ and the nitrogen flow controlled by an optical emission monitor (OEM) set at 50\%; the average deposition pressure was $1.55 \pm 0.15 \mathrm{mTorr}$. The bi-layer period of the coatings was changed by altering the specimen table rotation speed from 2 to $6 \mathrm{rpm}$. The deposition time was set for $5 \mathrm{~h}$ to achieve relatively thick coatings of $12-13 \mu \mathrm{m}$. Prior to coating, the substrate materials were ultrasonically cleaned in acetone and alcohol, followed by ion-cleaning in vacuum. A pulsed DC bias of $-40 \mathrm{~V}$ was applied to the substrates and no extra heating was used during the deposition process.

X-ray diffraction using a $\mathrm{Cu} \mathrm{K}_{\alpha}$ source was applied to measure the superlattice bi-layer periods and to identify the coating crystallographic structures. In particular, the bi-layer periods $(\Lambda)$ were derived from satellite peak positions [11]. The XRD measurements were complemented by a texture evaluation utilizing pole figures.

The mechanical properties of the coatings were measured with a nano-indentation tester using a maximum load of $30 \mathrm{mN}$. The test conditions corresponded to maximum indentation depths of $<10 \%$ of the coating thickness to minimize the substrate's influence on the measurement. The hardness $(H)$ and Young's modulus $(E)$ of the coatings were derived from the loading/unloading curves generated with a Berkovich indenter using the Oliver-Pharr method [12]. Seven indentations were performed on each sample to generate the average $H$ and $E$ values.

ASTM G76-02, Standard Test Method for Conducting Erosion Tests by Solid Particle Impingement Using Gas Jets, was used as the erosion testing reference. The erosion testing was performed at room temperature using angular $\mathrm{Al}_{2} \mathrm{O}_{3}$ powders with an average size of $50 \mu \mathrm{m}$. The average velocity of abrasive particles was controlled at $84 \mathrm{~m} / \mathrm{s}$ while the particle feed rate was regulated at $1-2 \mathrm{~g} / \mathrm{min}$. The impingement angle was set at $90^{\circ}$. The weight of a tested sample was measured at different exposure periods, and the mass loss erosion rate $(\mathrm{mg} / \mathrm{g})$ was calculated by dividing the total weight loss with the total amount of erodent used; volume loss erosion rate was obtained by dividing the mass loss erosion rate by the specific density of the coating.

\section{Results}

Crystallographic Structure

Figure 1 presents the XRD spectra of the coatings deposited on the 410SS and Ti-6Al-4V substrates at different rotation speeds. Instead of having two sets of diffraction peaks originated from $\mathrm{TiN}$ and $\mathrm{VN}$ layers, all coatings exhibit only one set of peaks and have a face-centered cubic B1 structure, the same as monolithic TiN. Positive and negative satellite peaks can be observed on both sides of the main Bragg reflections of the B1 structure, as labeled in Fig. 1. The satellite peak positions were used to calculate the bi-layer periods of the superlattices, and the average values are presented in Fig. 2 . The bi-layer period $(\Lambda)$ of the TiN/VN coatings varied between 3.4 and $\sim 11.0 \mathrm{~nm}$, and was approximately inversely proportional to the table rotation speed. No influence of substrate materials on
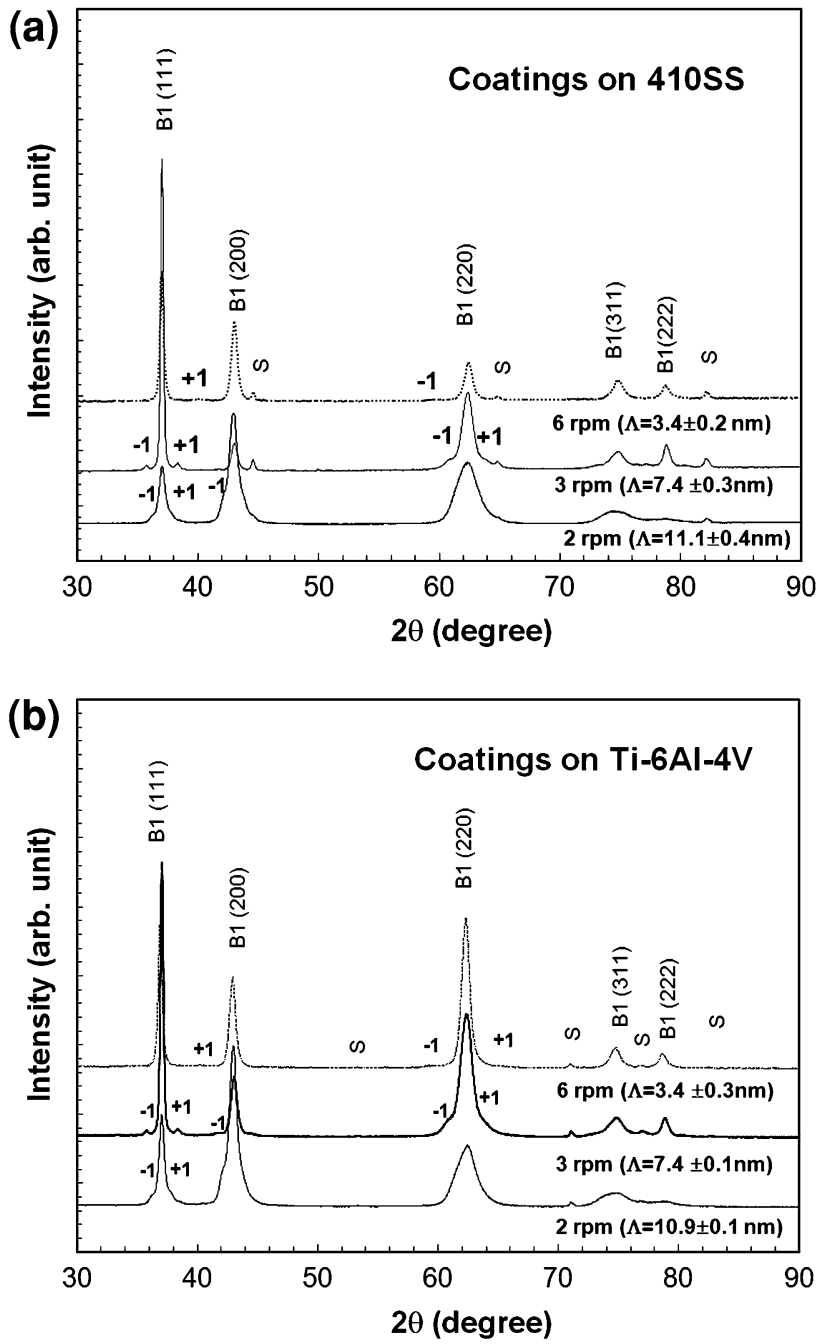

Fig. 1 XRD spectra of TiN/VN coatings deposited on a 410SS and b $\mathrm{Ti}-6 \mathrm{Al}-4 \mathrm{~V}$ 
bi-layer period was observed, as the coatings on two substrates deposited at the same table rotation speed showed almost identical bi-layer period values.

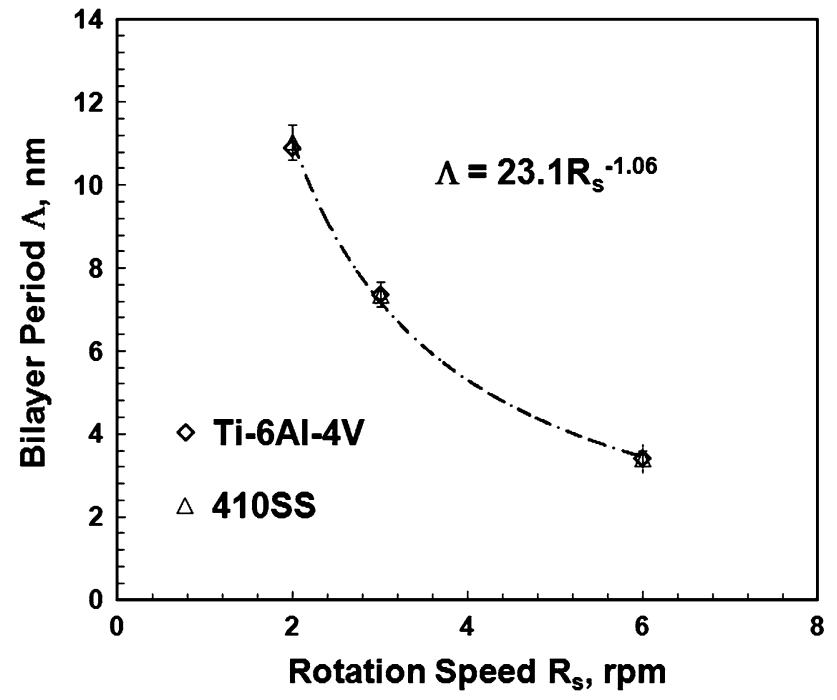

Fig. 2 Bilayer period of TiN/VN coatings as a function of table rotation speed

Table 1 The relative intensities of (111), (200), and (220) main peaks

\begin{tabular}{lllll}
\hline $\begin{array}{l}\text { Bi-layer period, } \\
\mathrm{nm}\end{array}$ & Substrate & \multicolumn{3}{c}{ Relative peak intensity } \\
\cline { 3 - 5 } & & $(111)$ & $(200)$ & $(220)$ \\
\hline 3.4 & $410 \mathrm{SS}$ & 1 & 0.61 & 0.29 \\
& Ti-6Al-4V & 1 & 0.63 & 1.06 \\
7.4 & $410 \mathrm{SS}$ & 1 & 0.09 & 0.2 \\
& Ti-6Al-4V & 1 & 0.22 & 0.45 \\
$\sim 11.0$ & $410 \mathrm{SS}$ & 1 & 2.11 & 1.24 \\
& Ti-6Al-4V & 1 & 1.72 & 0.68 \\
\hline
\end{tabular}

As the bi-layer period changed, the relative intensities of the peaks varied, but in a different manner for the coatings on the 410SS and Ti-6Al-4V substrates, indicating that both bi-layer period and substrate materials influenced the texture of the coatings. The peak intensities of the (111), (200), and (220) main peaks were measured and then normalized using the (111) peak intensity as a reference, and the results are presented in Table 1. A significant difference in the XRD spectra was observed at $\Lambda=3.4 \mathrm{~nm}$, where the (220) peak intensity was much stronger for the coating on Ti-6Al-4V than on 410SS substrate. At $\Lambda=7.4 \mathrm{~nm}$, the (111) peak appeared to be the strongest for the coatings on both substrates; and the coating on Ti-6Al-4V appeared to have a notably stronger (220) peak than that on 410SS. When $\Lambda=11 \mathrm{~nm}$, the coatings on both $410 \mathrm{SS}$ and Ti-6Al-4V substrates, having the (200) reflection as the strongest peak, demonstrated much broader peaks than those with different bi-layer periods.

The XRD measurements were complemented by texture evaluation through pole figures, which confirmed the above observations. Figure 3 presents the pole figures of the coatings with $\Lambda=3.4 \mathrm{~nm}$ on $410 \mathrm{SS}$ (Fig. 3a) and Ti-6Al$4 \mathrm{~V}$ substrates (Fig. $3 \mathrm{~b}$ ), which clearly demonstrates the difference in the texture between these two coatings.

\section{Surface Morphology}

The surface morphologies of the TiN/VN coatings on Ti-6Al-4V and 410SS substrates were examined under a scanning electron microscope. Clear differences in surface features were observed for the coatings with $\Lambda=3.4 \mathrm{~nm}$; when compared with the coating on 410SS (Fig. 4a, with a surface roughness of $R_{\mathrm{a}}=16.5 \pm 2.2 \mathrm{~nm}$ ), the coating on
Fig. 3 Pole figure plots for the TiN/VN coatings with $\Lambda=\sim 11 \mathrm{~nm}$ on a 410SS and b $\mathrm{Ti}-6 \mathrm{Al}-4 \mathrm{~V}$ (a)
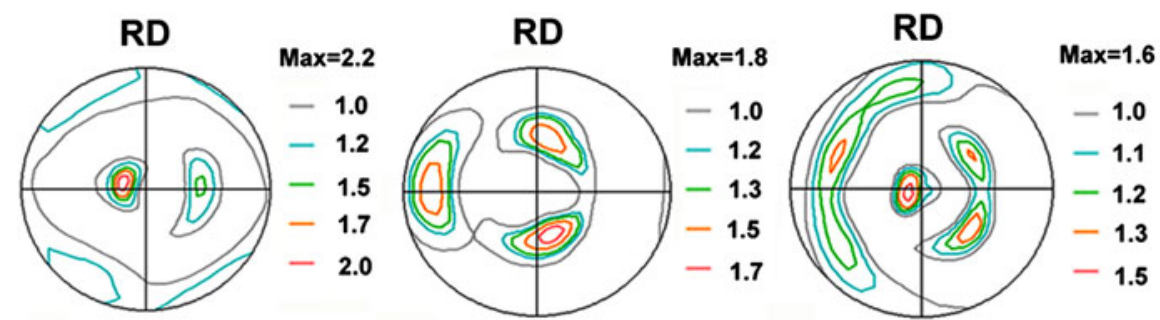

(b)

TD

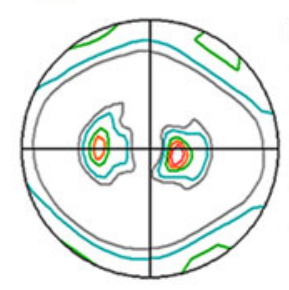

$\{111\}$

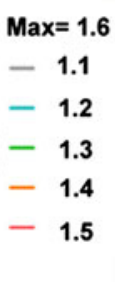

1.5

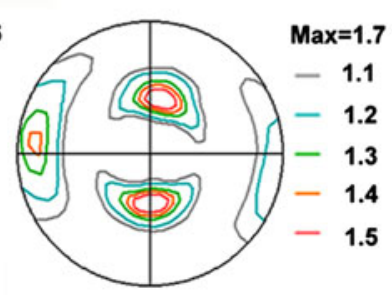

$\{200\}$

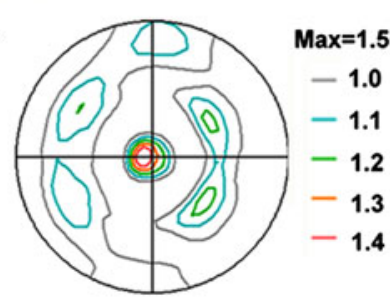

\{220\} 
Ti-6Al-4V substrate (Fig. 4b) was rougher $\left(R_{\mathrm{a}}=21.4 \pm\right.$ $2.4 \mathrm{~nm}$ ) with a more apparent faceted growth feature. At $\Lambda=7.4 \mathrm{~nm}$, the coatings on both substrates became denser, but still had large grains (Fig. 4c, d); and the coating on
410SS appeared smoother than the coating on Ti-6Al-4V. At $\Lambda=11 \mathrm{~nm}$, both titanium and stainless steel substrates demonstrated similar coating surface morphologies with dense and fine structured grains, as shown in Fig. 4(e), (f).
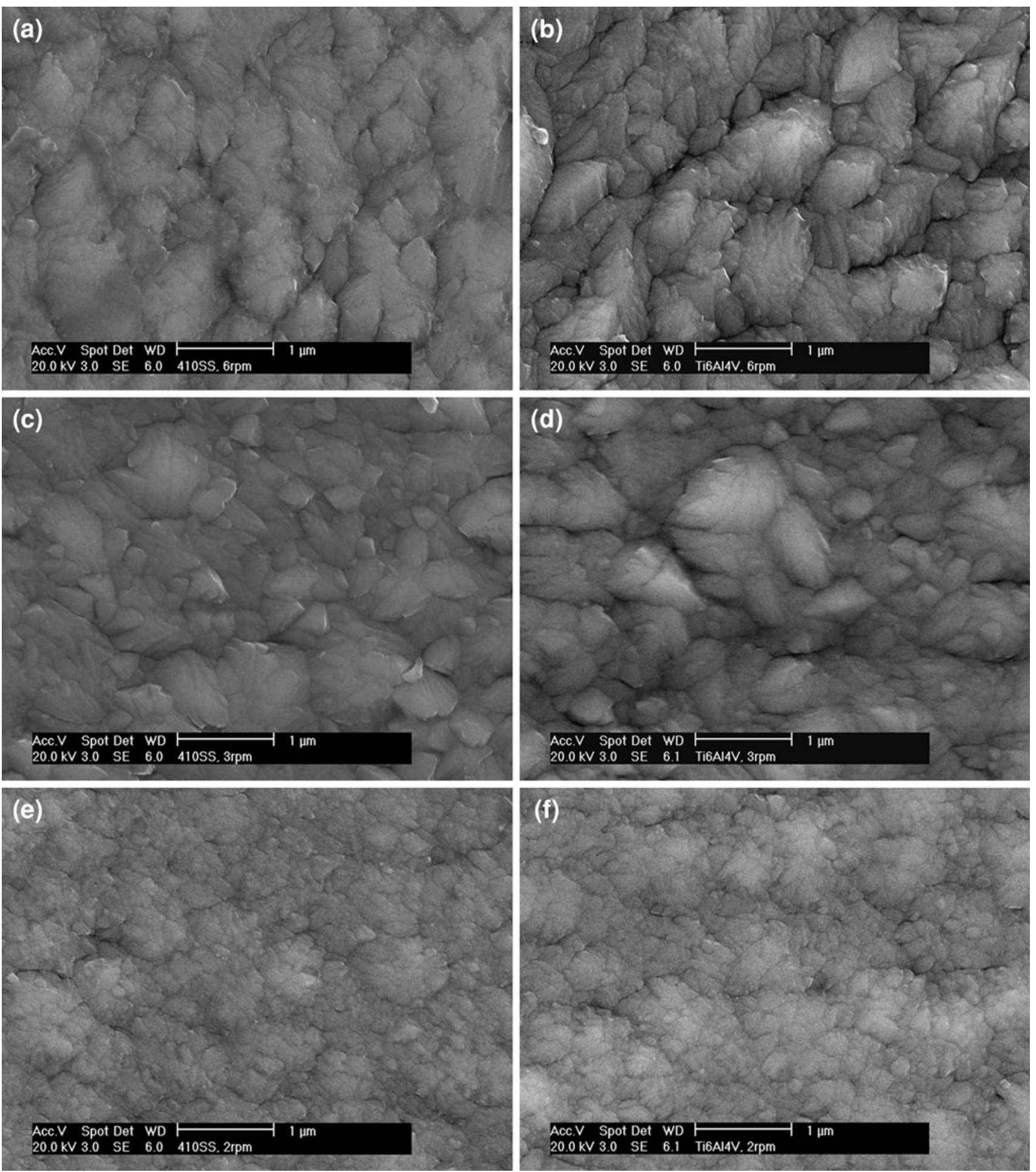

Fig. 4 SEM images of TiN/VN coatings with bi-layer period of $3.4 \mathrm{~nm}$ (on a $410 \mathrm{SS}$ and $\mathbf{b} \mathrm{Ti}-6 \mathrm{Al}-4 \mathrm{~V}$ ), $7.4 \mathrm{~nm}$ (on $\mathbf{c} 410 \mathrm{SS}$ and $\mathbf{d} \mathrm{Ti}-6 \mathrm{Al}-4 \mathrm{~V}$ ), and $\sim 11.0 \mathrm{~nm}$ (on e 410SS and $\mathbf{f} \mathrm{Ti}-6 \mathrm{Al}-4 \mathrm{~V}$ ) 

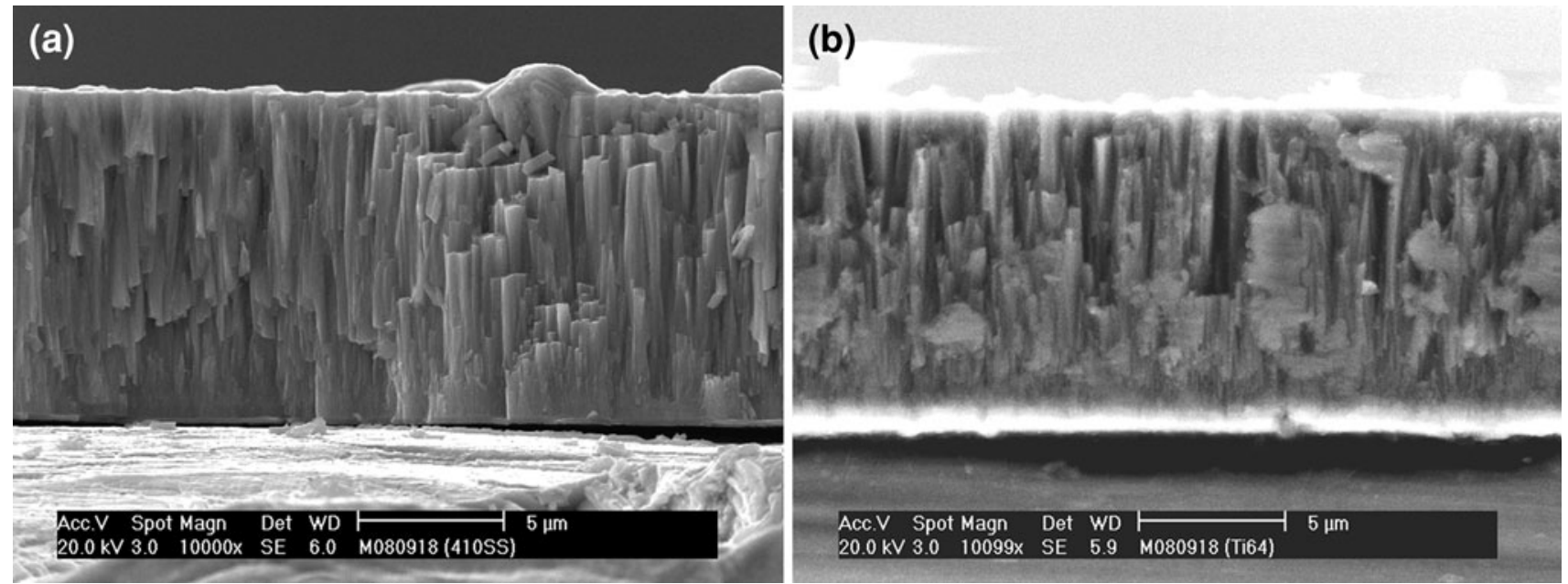

Fig. 5 The cross-sectional SEM images showing the fracture surfaces of the TiN/VN coatings (with $\Lambda=3.4 \mathrm{~nm}$ ) deposited on a $410 \mathrm{SS}$ and b $\mathrm{Ti}-6 \mathrm{Al}-4 \mathrm{~V}$

The coated samples were cross sectioned for further SEM analysis and measurement of coating thickness. The SEM images of the $\Lambda=11 \mathrm{~nm}$ coating fracture surfaces are shown in Fig. 5, and illustrate the columnar structure of the coatings. The coating thicknesses, $12.1 \pm 0.1$ and $11.9 \pm 0.1 \mu \mathrm{m}$ for the coatings on 410SS and Ti-6Al-4 V, respectively, are independent of the substrate materials.

\section{Mechanical Properties}

The values of hardness $(H)$ and elastic modulus $(E)$ as a function of the bi-layer period for the TiN/VN coatings on 410SS and Ti-6Al-4V substrates are presented in Fig. 6(a) and (b), respectively. For both substrate materials, an increase in hardness was observed with an increase in the bi-layer period. Moreover, the coatings on different substrates had dissimilar values of hardness and elastic modulus, with higher $H$ and $E$ values for the coatings on 410SS than those on Ti-6Al-4V. Owing to the fact that the indentation tests were performed using a small load on the as-deposited coating surfaces, any surface feature deviating from the ideal mirror-polished surface condition, may lead to measurement errors, as shown by the error bars in Fig. 6 .

\section{Erosion Performance}

The erosion rates of the bare and coated samples are summarized in Fig. 7 with the experimental errors presented for those samples tested for 2 or 3 times. A higher erosion rate indicates a low erosion resistance. All coated samples demonstrated substantially lower erosion rates than the uncoated substrates; the erosion rate of the bare Ti-6Al-4V is $2-4$ times higher than that of the TiN/VN coatings on Ti-6Al-4V. Similarly, the erosion rate of the
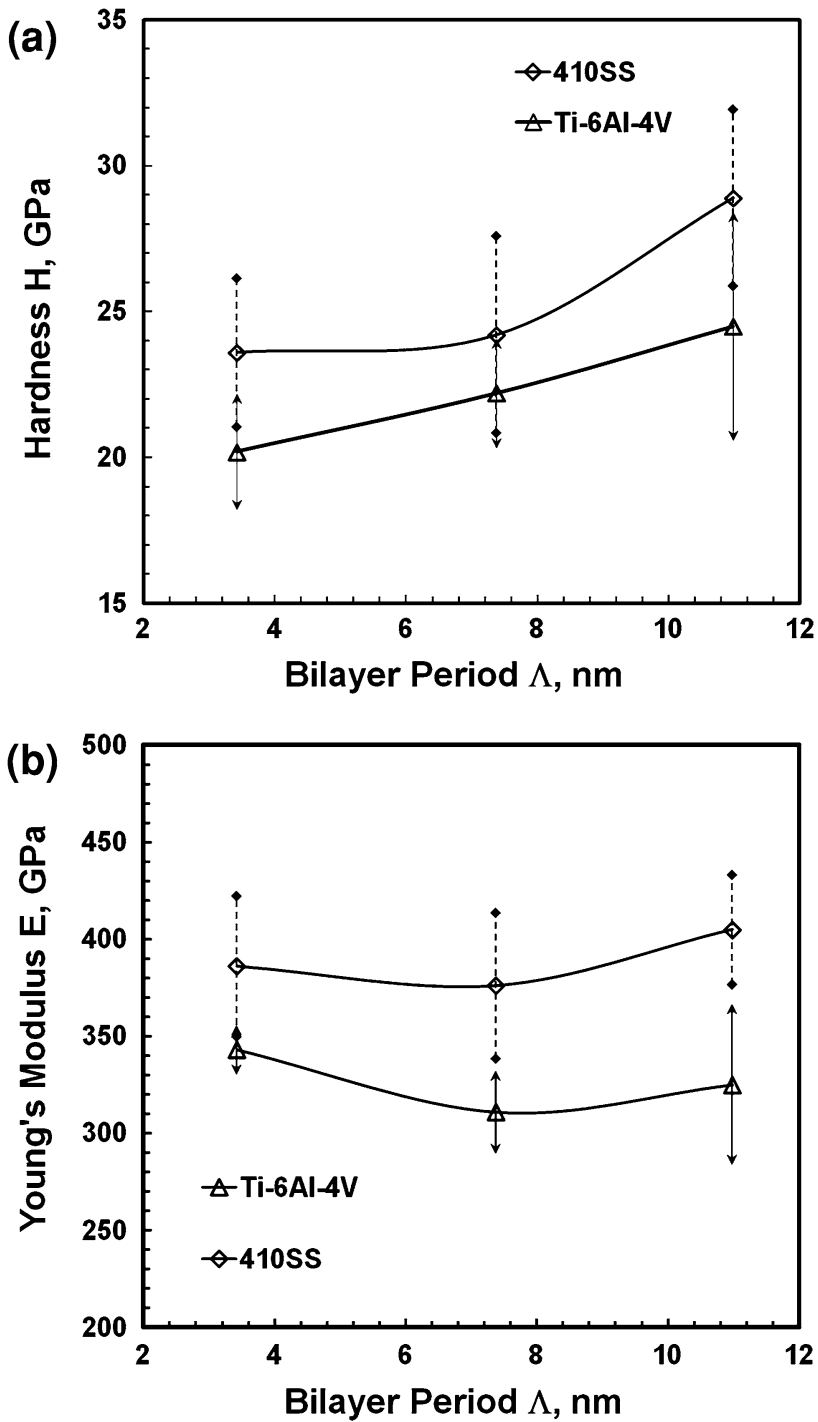

Fig. 6 The hardness and Young's modulus values as a function of the bi-layer period of the TiN/VN coatings 


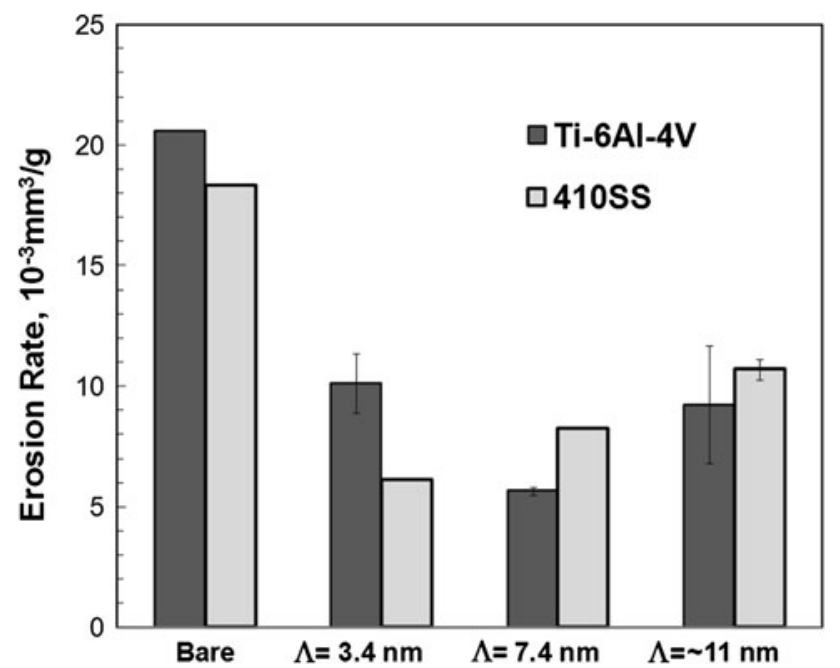

Fig. 7 The erosion rates of bare substrates and TiN/VN coatings

bare $410 \mathrm{SS}$ is $2-3$ times higher than the erosion rate of the TiN/VN coatings on 410SS.

\section{Discussion}

In a magnetron sputtering system, the magnetron source provides energetic ion bombardment to a growing film. Both ion bombardment energy and ratio of arrival ions and condensing atoms are considered as the most important parameters that affect the coating microstructure and correspondingly, its mechanical properties [13]. It was observed in this study that the different substrate materials, 401SS and $\mathrm{Ti}-6 \mathrm{Al}-4 \mathrm{~V}$, have a different influence on the coating microstructural characteristics, which can be attributed to the difference in ion bombardment to the growing films.

410SS is a martensitic, ferromagnetic alloy, while titanium alloy $\mathrm{Ti}-6 \mathrm{Al}-4 \mathrm{~V}$ is non-ferromagnetic. In a magnetized plasma, the magnetic field, which is affected by a ferromagnetic substrate, can penetrate through the substrate and trap more secondary electrons in a closed loop, leading to more ionization and excitation of gas atoms [14]. Therefore, a biased ferromagnetic substrate can attract more charged particles from plasma to its surface [15], leading to different surface morphologies and coating texture when compared to a non-ferromagnetic substrate counterpart [16]. Thus, the difference in coating texture and surface morphology for the ferromagnetic 410SS and non-magnetic Ti-6Al-4V substrates can be attributed to the difference in ion bombardments to the growing films. Ti-6Al-4V, for instance, received less energetic ion bombardment, and favoured a faceted growth of the coating [17].

For a superlattice coating, the modulation period and crystallographic orientation are known as two important
Table $2 \theta$ values of primary and secondary slip systems for different coating orientations

\begin{tabular}{llll}
\hline Orientation & $(111)$ & $(200)$ & $(220)$ \\
\hline Primary slip system & $35.3^{\circ}$ & $45.6^{\circ}$ & $0^{\circ}$ \\
Secondary slip system & $0^{\circ}$ & $54.7^{\circ}$ & $35.3^{\circ}$ \\
\hline
\end{tabular}

structural factors affecting coating hardness [18]. It has been reported that as the modulation period decreases, the hardness increases initially, reaches to a peak value and then decreases sharply [10, 18, 19]. The peak hardness usually appears at a bi-layer period of 3-10 nm.

However, it should be noted that this pattern of change in the hardness generally applies to superlattice coatings with the same preferred orientation. When the coating texture changes as the modulation period varies, the coating hardness may change in quite a different and complicated manner.

As the bi-layer period of the TiN/VN coatings was practically independent of the substrate materials as shown in Fig. 2, the hardness variations of the coatings on different substrates should not be attributed to the coating layout, but rather to other factors such as the coating crystallographic orientation.

The effect of superlattice preferred orientation on hardness enhancement can be explained using the following equation [20]:

$H_{\text {max }}-H_{\mathrm{A}}=\frac{3\left(G_{\mathrm{B}}-G_{\mathrm{A}}\right) \sin \theta}{m \pi^{2}}$,

where $H_{\max }$ is the maximum expected hardness of the superlattice, $H_{\mathrm{A}}$ is the hardness of the layer with a lower shear modulus, $G_{\mathrm{A}}$ and $G_{\mathrm{B}}$ are the shear moduli of the A and B layers, respectively, $m$ is the Taylor factor, and $\theta$ is the smallest angle between slip planes and layer interfaces. From Eq 1, it is obvious that the different $\theta$ angles for the highly anisotropic TiN/VN coatings on the different substrates certainly affect the superlattice hardness.

For B1 structured superlattices like TiN/VN, $\{110\}$ $\langle 1 \overline{1} 0\rangle$ is the primary slip system [21]. Given the complex stress states associated with compressive indentation testing, the secondary slip system $\{111\}\langle 1 \overline{1} 0\rangle$ is likely to activate as well and contribute to hardness enhancements $[22,23]$. As the (200) orientation has the largest $\sin \theta$ values for both primary and secondary slip systems (Table 2), a superlattice with a (200) texture should have more significant hardness enhancement than those with (111) or (220) texture. For example, a TiN/CrN superlattice with a (200) orientation can reach a peak hardness value of $39 \mathrm{GPa}$, while the (111) orientation produces a peak hardness of only about $27 \mathrm{GPa}[18]$. 
In this study, the TiN/VN coatings with a bi-layer period of $11 \mathrm{~nm}$ on $410 \mathrm{SS}$ and $\mathrm{Ti}-6 \mathrm{Al}-4 \mathrm{~V}$, which showed a significantly stronger (200) XRD peak compared to the coatings with other bi-layer periods, have high hardness values of 28.9 and $24.5 \mathrm{GPa}$, respectively. Decreasing the bi-layer period to $7.4 \mathrm{~nm}$ led to a significant drop in the intensity of (200) peak, which contributes to a drop in hardness values. As none of the coatings in this study demonstrated a dominant (200) texture, the highest coating hardness only reached $28.9 \mathrm{GPa}$, far lower than the peak hardness value of $\sim 55 \mathrm{GPa}$ observed from (200) oriented TiN/VN superlattices [19]. As the coatings with bi-layer periods of 3.4 and $7.4 \mathrm{~nm}$ on Ti-6Al-4V substrate grew more favorably along the (220) direction than those on 410SS, it is expected that they are softer than the coatings on 410SS.

The dense coating structure and possible high residual compressive stress, resulting from more energetic ion bombardment, are also factors contributing to the higher hardness of the coatings on the ferromagnetic 410SS. The difference in coating microstructure and mechanical properties likely leads to the difference in erosion performance of the coatings.

\section{Conclusions}

Nano-structured TiN/VN coatings with a range of bi-layer periods from 3.4 to $\sim 11.0 \mathrm{~nm}$ were deposited on ferromagnetic 410 stainless steel and non-ferromagnetic Ti-6Al-4V substrates; substrate type demonstrated a strong influence on microstructural, mechanical, and erosion properties of the coatings. As XRD data demonstrated, the preferred orientations of the coatings on martensitic 410SS and Ti-6Al-4V were dissimilar, especially for the coatings with $\Lambda=3.4 \mathrm{~nm}$. It was found that values of hardness increased with the bi-layer period of the coatings and there were clear differences between the coatings on different substrates. The coatings on 410SS are considerably harder $(H=23.6-28.9 \mathrm{GPa})$ than their counterparts on Ti-6Al-4V $(H=20.2-24.5 \mathrm{GPa})$. While the erosion resistances of the TiN/VN coatings on both substrates were 2-4 times better than the bare substrates, the influence of substrates on erosion performance was also observed. The differences in microstructural, mechanical, and erosion properties were attributed to the more energetic ion bombardment to the coatings on ferromagnetic 410SS than those on non-ferromagnetic Ti-6Al-4V during the UMS deposition process.

Acknowledgments The authors wish to acknowledge NRC Aerospace and NSERC for their financial support under CRIAQ Project
1.20, and Mr. Duanjie Li from the Department of Mining and Materials Engineering of McGill University, Montreal, Canada for the technical support in obtaining the texture pole figures.

\section{References}

1. V.R. Paramesvaran, J.P. Immarigeon, D. Nagy, Titanium nitride coating for aero engine compressor gas path components. Surf. Coat. Technol. 52, 251 (1992)

2. W. Tabakoff, Protection of coated superalloys from erosion in turbomachinery and other systems exposed to particulate flows. Wear 233-235, 200 (1999)

3. M. Klein, G. Simpson, The development of innovative methods for erosion testing a Russian coating on GE T64 gas turbine engine compressor blades. Proc. of the ASME Turbo Expo, 2004, Paper No. GT2004-54336

4. M. Bielawski, W. Beres, FE modelling of surface stresses in erosion-resistant coatings under single particle impact. Wear $\mathbf{2 6 2}$, 167 (2007)

5. S. Hassani, M. Bielawski, W. Beres, L. Martinu, M. Balazinski, J.E. Klemberg-Sapieha, Design of hard coating architecture for the optimization of erosion resistance. Wear 265, 879 (2008)

6. S. Veprek, M. Jilek, Super- and ultrahard nanocomposite coatings: generic concept for their preparation, properties and industrial applications. Vacuum 67, 443 (2002)

7. S. Hassani, M. Bielawski, W. Beres, L. Martinu, M. Balazinski, J.E. Klemberg-Sapieha, Predictive tools for the design of erosion resistant coatings. Surf. Coat. Technol. 203, 204 (2008)

8. J. Musil, F. Kunc, H. Zeman, H. Polakova, Relationships between hardness, Young's modulus and elastic recovery in hard nanocomposite coatings. Surf. Coat. Technol. 154, 304 (2002)

9. K. Chen, M. Bielawski, Interfacial fracture toughness of transition metal nitrides. Surf. Coat. Technol. 203, 598 (2008)

10. U. Helmersson, S. Todorova, S.A. Barnett, J.-E. Sundgren, L.C. Markert, J.E. Greene, Growth of single-crystal TiN/VN strainedlayer superlattices with extremely high mechanical hardness. J. Appl. Phys. 62, 481 (1987)

11. Q. Yang, L.R. Zhao, Characterization of nano-layered multilayer coatings using modified Bragg law. Mater. Charact. 59, 1285 (2008)

12. W.C. Oliver, G.M. Pharr, An improved technique for determining hardness and elastic modulus using load and displacement sensing indentation experiments. J. Mater. Res. 7, 1564 (1992)

13. R.P. Howson, H.A. J'Afer, A.G. Spencer, Substrate effects from an unbalanced magnetron. Thin Solid Films 19(3/194), 127 (1990)

14. J. Faber, G. Hötzsch, Chr Metzner, Sputter etching of steel substrates using DC and MF pulsed magnetron discharges. Vacuum 64, 55 (2002)

15. L. Bárdos, H. Baránková, L.-E. Gustavsson, Effect of substrate material and bias on properties of TiN films deposited in the hybrid plasma reactor. J. Vac. Sci. Technol. A 24, 1655 (2006)

16. L. Bárdoš, L.-E. Gustavsson, H. Baránková, Effect of ferromagnetic substrates on the film growth in magnetized plasma systems. Surf. Coat. Technol. 200, 1862 (2005)

17. P.H. Mayrhofer, C. Mitterer, J. Musil, Structure-property relationships in single- and dual-phase nanocrystalline hard coatings. Surf. Coat. Technol. 174-175, 725 (2003)

18. Q. Yang, C. He, L.R. Zhao, J.-P. Immarigeon, Preferred orientation and hardness enhancement of TiN/CrN superlattice coatings deposited by reactive magnetron sputtering. Scripta Mater. 46, 293 (2002) 
19. M. Shinn, L. Hultman, S.A. Barnett, Growth, structure, and microhardness of epitaxial TiN/NbN superlattices. J. Mater. Res. 7, 901 (1992)

20. P.C. Yashar, W.D. Sproul, Nanometer scale multilayered hard coatings. Vacuum 55, 179 (1999)

21. L. Hultman, M. Shinn, P.B. Mirkarimi, S.A. Barnett, Characterization of misfit dislocations in epitaxial (001)-oriented TiN,
$\mathrm{NbN}, \mathrm{VN}$, and $(\mathrm{Ti}, \mathrm{Nb}) \mathrm{N}$ film heterostructures by transmission electron microscopy. J. Cryst. Growth 135, 309 (1994)

22. P. Yashar, S.A. Barnett, J. Rechner, W.D. Sproul, Structure and mechanical properties of polycrystalline $\mathrm{CrN} / \mathrm{TiN}$ superlattices. J. Vac. Sci. Technol. A 16, 2913 (1998)

23. Z. Wokulski, Mechanical properties of TiN whiskers. Phys. Status Solidi A 120, 175 (1990) 